\title{
PENGARUH LINGKUNGAN KERJA DAN KARAKTERISTIK INDIVIDU TERHADAP KINERJA PEGAWAI BANK BRI SYARIAH KABUPATEN SUBANG
}

\author{
Opan Arifudin \\ Ekonomi Syariah, STEI Al-Amar Subang \\ Email: opan.arifudin@steialamar.ac.id \\ Fenny Damayanti Rusmana \\ Perbankan Syariah, STEI Al-Amar Subang \\ Email: fenny.damayanti@steialamar.ac.id
}

\begin{abstract}
An Islamic banking institution that wants to carry out its duties and functions well, will try to change its employees so that they have good performance. This is done so that its employees are more productive in carrying out their duties and responsibilities. To get employees in accordance with what is expected, it is necessary to have a working environment that supports the implementation of tasks, namely the work environment in terms of infrastructure, as well as the general environment, namely the community in Islamic banking institutions. Data collection methods in research are methods or methods used by researchers to obtain data in a study. Data collection methods in this study using the Questionnaire Method. the significance value of Individual Characteristics is 0,000 smaller than the significance level ( $\alpha$ ) 0.05. Because the value of $t$ count $>t$ table $(5.632>2.020)$ and the significance value is smaller than the significance level $(\alpha) 0.05(0.000<0.05)$, the second hypothesis is accepted, meaning that Individual Characteristics has a positive and significant effect on employee performance. The third hypothesis is accepted, meaning that the Work Environment and Individual Characteristics simultaneously have a positive and significant effect on employee performance. This is shown because the calculated $F$ value $>F$ table (34.254> 3.226) and the significance value is smaller than the significance level $(\alpha) 0.05(0.000<0.05)$.
\end{abstract}

Keywords: Work Environment, Individual

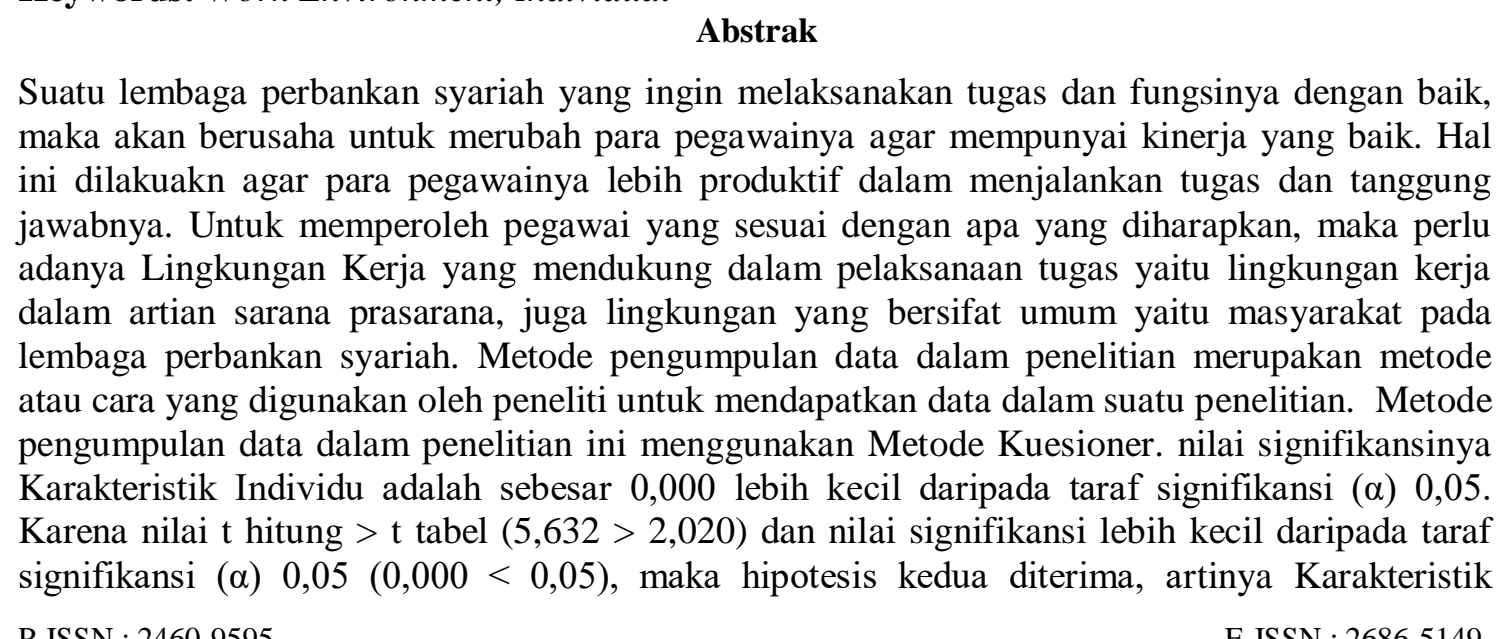


36 | Opan Arifudin, Fenny Damayanti Rusmana, PENGARUH LINGKUNGAN KERJA DAN KARAK....

Individu berpengaruh positif dan signifikan terhadap kinerja pegawai. Hipotesis ketiga diterima, artinya Lingkungan Kerja dan Karakteristik Individu secara simultan berpengaruh positif dan signifikan terhadap kinerja pegawai. Hal ini di tunjukan Karena nilai F hitung > F tabel $(34,254$ $>3,226)$ dan nilai signifikansi lebih kecil daripada taraf signifikansi $(\alpha) 0,05(0,000<0,05)$.

Kata Kunci: Lingkungan Kerja, Karakteristik Individu

\section{Dasar Pemikiran}

Pada umumnya setiap instansi dalam menjalankan kegiatan operasionalnya membutuhkan beberapa faktor yang mendukung untuk tercapainya kinerja yang baik dan produktifitas yang tinggi. Sumber daya manusia yang diantaranya dicerminkan dari karakteristik SDM atau Pegawai merupakan salah satu faktor terpenting, karena tanpa adanya peran dari sumber daya manusia yang berkualitas, segala aktifitas dalam suatu instansi tidak akan dapat terlaksana secara optimal Setiap instansi harus menyadari berhasil atau tidaknya tugas dan fungsi yang dilaksanakan tergantung pada faktor sumber daya manusia (SDM). Sumber daya manusia yaitu orang-orang yang memberikan tenaga, bakat, kretifitas dan usahanya kepada organisasi, perusahaan atau instansi. Bagaimanapun canggihnya sarana dan prasarana yang dimiliki oleh suatu instansi tanpa ditunjang dengan kemampuan pegawai, mustahil instansi tersebut dapat maju dan berkembang. Menurut (Arifudin, 2020) organisasi yang baik, tumbuh dan berkembang akan menitikberatkan pada sumber daya manusia (human resources) guna menjalankan fungsinya dengan optimal, khususnya menghadapi dinamika perubahan lingkungan yang terjadi.

Suatu instansi yang ingin melaksanakan tugas dan fungsinya dengan baik, maka instansi tersebut akan berusaha untuk merubah para pegawainya agar mempunyai mutu serta kinerja yang baik, sehingga membuat para pegawainya lebih produktif dalam menjalankan tugas dan tanggung jawab mereka. Menurut (Arifudin, 2019) karyawan adalah setiap orang yang bekerja dengan menjual tenaganya (Fisik dan Pikiran) kepada suatu perusahan dan memperoleh balas jasa sesuai dengan peraturan dan perjanjian. Untuk memperoleh pegawai yang sesuai dengan apa yang diharapkan, maka perlu adanya Lingkungan Kerja yang mendukung dalam pelaksanaan tugas yaitu lingkungan 
ISLAMIC BANKING: Jurnal Pemikiran dan Pengembangan Perbankan Syariah, Volume 6 Nomor 1 Edisi Agustus 2020

kerja dalam artian sarana prasarana, juga lingkungan yang bersifat umum yaitu masyarakat.

Lingkungan kerja merupakan penunjang yang sangat besar bagi terciptanya proses aktifitas sebuah pekerjaan. Dengan lingkungan kerja yang baik atau menciptakan kondisi kerja yang baik, hal ini mampu memberikan motivasi karyawan untuk bekerja dengan penuh semangat. Menurut (Rahmawanti et al., 2014) lingkungan kerja adalah segala sesuatu yang ada disekitar para pekerja yang dapat mempengaruhi dirinya dalam menjalankan tugastugas yang dibebankan.

Menurut karakteristik individu adalah setiap orang mempunyai pandangan, tujuan, kebutuhan dan kemampuan yang berbeda satu sama lain. Perbedaan ini akan terbawa dalam dunia kerja, yang akan menyebabkan kepuasan satu orang dengan yang lain berbeda pula, meskipun bekerja ditempat yang sama. Karakteristik individu meliputi kemampuan, nilai, sikap, dan minat. Pengembangan karakteristik pegawai merupakan suatu usaha yang penting dalam instansi, karena dengan karakteristik pegawai yang baik suatu instansi akan dapat maju dan berkembang. Pengembangan karakteristik pegawai dirancang untuk meningkatkan efisiensi dan efektifitas kerja, meningkatkan prestasi kerja, mengurangi absensi dan rotasi jabatan, serta memperbaiki kepuasan kerja. Para pegawai yang telah memperluas kecakapannya serta kemampuan kerja melalui program pengembangan kualitas pegawai akan memperoleh hasil dan mutu yang lebih baik dalam melaksanakan tugas dan fungsinya.

Menurut (Alam, 2016) karyawan yang memiliki kinerja yang tinggi adalah dia yang berbakat, berkualitas, bermotivasi tinggi dan mau bekerja sama dalam team. Berdasarkan pengertian kinerja, kinerja merupakan hasil kerja yang dicapai oleh seorang karyawan dengan standar yang telah ditentukan. Dengan merujuk kepada Tafsir Inspirasi karya Zainal Arifin Zakaria, pada surat Al-Lail ayat 2 yang artinya "demi siang apabila terang benderang". Dalam tafsir tersebut dijelaskan bahwa siang adalah masa untuk bekerja, dan kerja adalah sebagian dari pengertian ibadah bagi seorang mukmin, kapan dan dimana saja selama niatnya untuk Allah. Ayat di atas didukung oleh referensi lain dari surat Al-Ashr ayat 1-3 Allah berfirman yang artinya "demi masa. 


\section{Opan Arifudin, Fenny Damayanti Rusmana, PENGARUH LINGKUNGAN KERJA DAN KARAK....}

Sesungguhnya manusia itu benar-benar dalam kerugian, kecuali orang-orang yang beriman dan mengerjakan amal saleh dan nasehat menasehati”.

Merujuk pada ayat-ayat di atas sebagai lembaga keuangan islam dan dengan pegawai beragama Islam, harus menjunjung tinggi nilai-nilai islam dalam menjalankan segala tanggung jawabnya. Namun pada kenyataannya, dari niat sebuah lembaga keuangan syariah dalam mengatur tatangan organisasinya masih saja ada terdapat pegawai yang belum bisa menerapkan semua aturan yang telah ditentukan.. Hal ini akan menjadi Penghambat dari semua program lembaga keuangan syariah dalam menghasilkan layanan perbankan yang bermutu. Oleh karena itu perlu diketahui Pengaruh Lingkungan Kerja Dan Karakteristik Individu Terhadap Kinerja Pegawai BRI Syariah Kabupaten Subang.

\section{Metode Penelitian}

Penelitian ini menerapkan metode penelitian kuantitatif. Adapun yang melatarbelakangi peneliti memilih metode penelitian kuantitatif karena sudah sesuai dengan tujuan penelitian yang ingin mengetahui Pengaruh Lingkungan Kerja Dan Karakteristik Individu Terhadap Kinerja Pegawai BRI Syariah Kabupaten Subang. Penelitian ini tergolong jenis penelitian kausal karena ingin mencari bagaimana dampak dari Pengaruh Lingkungan Kerja Dan Karakteristik Individu pada pegawai BRI Syariah dan dampak Terhadap Kinerja Pegawai BRI Syariah Kabupaten Subang.

Metode pengumpulan data dalam penelitian merupakan metode atau cara yang digunakan oleh peneliti untuk mendapatkan data dalam suatu penelitian. Metode pengumpulan data dalam penelitian ini menggunakan Metode Kuesioner. Kuesioner adalah sejumlah pertanyaan secara tertulis yang akan dijawab oleh responden penelitian, agar peneliti memeroleh data lapangan/ empiris untuk memecahkan masalah penelitian dan menguji hipotesis yang telah ditetapkan. Dalam penelitian ini, kuesioner yang digunakan adalah kuesioner tertutup yaitu model pertanyaan dimana pertanyaan tersebut telah tersedia jawaban, sehingga responden hanya memilih dari alternatif jawaban yang sesuai dengan pendapat atau pilihannya. Pertanyaan tertutup tersebut menerangkan tanggapan responden terhadap variabel lingkungan kerja, karakteristik individu dan 
kinerja karyawan BRI Syariah. Untuk penskoran dari tiap jawaban yang diberikan oleh responden, peneliti menentukan sebagai berikut:

Untuk jawaban Sangat Tidak Setuju (STS)

Untuk jawaban Tidak Setuju (TS)

Untuk jawaban Ragu-ragu/ netral (R/N)

Untuk jawaban Setuju (S)

Untuk jawaban Sangat Setuju (SS)

Jawaban responden Variabel X1, X2, dan Y dari setiap pernyataan diskor sesuai dengan criteria diatas, kemudian dijumlahkan untuk mengetahui nilai Variabel X1,X2 dan Y. Selanjutnya dari perhitungan nilai kuesioner dapat dilihat Apakah Variabel X1, $\mathrm{X} 2$ dan Y sudah memiliki kriteria atau belum, hal ini dapat diketahui dengan menggunakan kelas interval, kelas interval ini bersumber dari nilai kuesioner yang tertinggi dan terendah dari Variabel $\mathrm{X} 1, \mathrm{X} 2$ dan $\mathrm{Y}$ yang didapat dengan cara mengalihkan jumlah Kuesioner, jumlah pertanyaan Variabel serta nilai sekor tertinggi dar terendah dari Variabel X1, X2 dan Y sebagai berikut :

Variabel X1 (Lingkungan Kerja)

Total Kuesioner tertinggi: $30 \times 9 \times 5=1.350$

Total Kuesioner tertinggi: $30 \times 9 \times 1=270$

Kemudian kedua nilai tersebut yaitu 1.350 dan 270 diselisihkan lalu dibagi 5 $(1.350-270: 5=216)$, sehingga diperoleh nilai dari masing-masing kelas interval untuk variable $\mathrm{X} 1$ yang dimaksud adalah bila total nilai kuesioner yang didapat :

216 - 432 maka Variabel X1 dinilai tidak memadai

433 - 649 maka Variabel X1 dinilai kurang memadai

650 - 866 maka Variabel X1 dinilai cukup memadai

867 - 1083 maka Variabel X1 dinilai memadai

1084 - 1300 maka Variabel X1 dinilai sangat memadai

Variabel X2 (Karakteristik Individu)

Total Kuesioner tertinggi: 30 x 12 × $5=2.160$

Total Kuesioner tertinggi: $30 \times 12 \times 1=432$ 
40 Opan Arifudin, Fenny Damayanti Rusmana, PENGARUH LINGKUNGAN KERJA DAN KARAK....

Kemudian kedua nilai tersebut yaitu 2.160 dan 432 diselisihkan lalu dibagi 5 (2.160-432: $5=346)$, sehingga diperoleh nilai dari masing-masing kelas interval untuk variable X2 yang dimaksud adalah bila total nilai kuesioner yang didapat :

432 - 778 maka Variabel X2 dinilai tidak memadai

779 - 1.125 maka Variabel X2 dinilai kurang memadai

1.126 - 1.472 maka Variabel X2 dinilai cukup memadai

1.473 - 1.819 maka Variabel X2dinilai memadai

1.820 - 2.166 maka Variabel X2 dinilai sangat memadai

Variabel Y (Kinerja Karyawan )

Total Kuesioner tertinggi: 30 × 9 × $5=1.350$

Total Kuesioner tertinggi: $30 \times 9 \times 1=270$

Kemudian kedua nilai tersebut yaitu 2.340 dan 468 diselisihkan lalu dibagi 5 $(2.340-468: 5=374)$, sehingga diperoleh nilai dari masing-masing kelas interval untuk variable Y yang dimaksud adalah bila total nilai kuesioner yang didapat :

468 - 842 maka Variabel dinilai tidak memadai

843 - 1.217 maka Variabel Y dinilai kurang memadai

1.218 - 1.592 maka Variabel Y dinilai cukup memadai

1.592 - 1.967 maka Variabel Y dinilai memadai

1.968 - 2.342 maka Variabel Y dinilai sangat memadai

Analisis Regresi Berganda

Model ini merupakan model regresi berganda dimana untuk mengetahui persamaan regresi pengaruh lingkungan kerja dan karakteristik individu terhadap kinerja karyawan pada BRI Syariah. Modelnya adalah terdiri dari dua persamaan.

Teknik Regresi berganda digunakan untuk mengetahui tingkat adanya pengaruh Variabel X1, X2, dan Y, adapun rumus yang digunakan adalah sebagai berikut :

Dimana:

Y : Variabel terikat (Kinerja Karyawan)

A : Bilangan Konstanta

b1 + b2 : Koefisien arah Regresi

X1 : Variabel Bebas (Lingkungan Kerja) 
X2 : Variabel Bebas (Karakteristik Individu)

Dari persamaan tersebut diatas dapat diuraikan dengan rumus :

$\sum \mathrm{y}=\mathrm{a}+\mathrm{b} 1 \sum \mathrm{X} 1+\mathrm{b} 2 \sum \mathrm{X} 2$

$\sum \mathrm{X} 1 \mathrm{Y}=\mathrm{a} \sum \mathrm{X} 1+\mathrm{b} 1 \sum \mathrm{X} 1+\mathrm{b} 2 \sum \mathrm{X} 2$

$\sum X 2 Y=a \sum X 2+b 1 \sum X 1+b 2 \sum X 2$

\section{Perhitungan Uji Statistik}

1. Uji Simultan (Uji F )

Uji Hipotesis secara simultan diantara kopentensi dan independensi karakteristik individu terhadap kinerja karyawan BRI Syariah. Uji Hipotesis ini dilakukan untuk mengetahui signifikansi pengaruh seluruh Variabel independen terhadap variable dependen. Untuk menghitungnya digunakan rumus:

$\mathrm{F}=($ RJK-Regresi $) /($ RJK-Sisa $)$
Atau dapat juga dicari dengan rumus:
F hitung=(k2/k)/((1-R2)/n-k-1)
$\begin{array}{ll}\text { Dimana } \\ \text { JK Regresi } & : \sum(\mathrm{i}=1)^{\wedge} \mathrm{n}(\mathrm{yi}-\mathrm{y}) 2 \\ \text { JK Total } & : \sum(\mathrm{i}=1)^{\wedge} \mathrm{n}(\mathrm{yi}-\mathrm{y}) 2 \\ \text { JK sisa } & : \text { JK total }-\mathrm{JK} \text { Regresi } \\ \text { kJK sisa } & : \text { JK sisa/ dk sisa } \\ \text { R2 } & : \text { Koefisien Determinan } \\ \mathrm{K} & : \text { Jumlah Variabel X } \\ \mathrm{N} & : \text { Banyaknya sampel }\end{array}$

Nilai $\mathrm{F}$ hitung dibandingkan dengan $\mathrm{F}$ table berdasarkan tingkat signifikan $(\mathrm{a})=5 \%$ dengan derajat pembilangan $\mathrm{v} 1-\mathrm{k}-1$, dan $\mathrm{V} 2=\mathrm{n}-\mathrm{k}$, sehingga dari variable distribusi $\mathrm{t}$ didapat nilai Ftabel

\section{Uji Parsial (Uji t)}

Dilakukan untuk mengetahui tingkat signifikansi pangaruh variable independen secara individual terhadap variable dependen. Nilai hitung dibandingkan dengan $\mathrm{t}$ table berdasrkan tingkat signifikansi (a): 5\% dengan derajat kebebasan n-2. 
42 Opan Arifudin, Fenny Damayanti Rusmana, PENGARUH LINGKUNGAN KERJA DAN KARAK....

Uji Hipotesis secara parsial antara X1 terhadap Y :

$\mathrm{t}=\mathrm{b} 1 / \mathrm{Sb} 1$

Uji Hipotesis secara parsial antara X2 terhadap Y:

$\mathrm{t}=\mathrm{b} 2 / \mathrm{Sb} 2$

Dimana :

bn : Koefisien Regresi masing-masing variabel $\mathrm{X}$

Sbn : Standar error masing-masing Variabel X

Nilai t hitung dibandingkan dengan $t$ tabel berdasrkan tingkat signifikansi (a) $=5 \%$ derajat kebebasan n-k-1

Koefisien

Pengujian dilakukan untuk mengetahui presentase besarnya variabel faktor independen ( X1) keahlian propesional ( X2) dan efektivitas penerapan struktur pengendalian internal $(\mathrm{Y})$ menggunakan koefisien determinan, dengan rumus :

$\mathrm{Kd}=\mathrm{r} 2 \times 100 \%$

Dimana :

Kd : Koefisien Determinan

rs : Koefisien Regresi

H0 akan diterima jika nilai signifikansi lebih besar dari 0.05

H0 akan ditolak jika nilai signifikansi lebih kecil dari 0.05

$\mathrm{KK}=\beta 1 \mathrm{LK}+\beta 2 \mathrm{SK}+\mathrm{e} 1$

Dimana:

$\mathrm{KK}$ = Kinerja Karyawan

$\mathrm{KI}=$ Karakteristik individu

LK = Lingkungan Kerja

(Augusty 2006, h.316)

Anak panah pada e1 menunjukan jumlah variance variabel Stres Kerja yang tidak dijelaskan oleh variabel Stres kerja dan Lingkungan Kerja. Besarnya nilai e1 $=\{(1$ R2)\}. 


\section{Pembahasan}

Hasil analisis korelasi ganda dalam penelitian ini diperolah angka $\mathrm{R}$ sebesar 0,791 , maka dapat disimpulkan bahwa terjadi hubungan yang kuat antara Lingkungan Kerja dan karakteristik individu terhadap kinerja karyawan BRI Syariah. Hasil analisis korelasi ganda (R) dapat dilihat pada tabel 5.12.

Analisis determinasi (R2) digunakan untuk mengetahui persentase sumbangan pengaruh variabel independen $(\mathrm{X} 1, \mathrm{X} 2)$ secara serentak terhadap variabel dependen $(\mathrm{Y})$. R2 sama dengan 0, maka tidak ada sedikit pun persentase sumbangan pengaruh yang diberikan variabel independen terhadap variabel dependen, sebaliknya R2 sama dengan 1, maka persentase sumbangan pengaruh yang diberikan variabel independen terhadap variabel dependen adalah sempurna.

Hasil analisis determinasi diperoleh angka R2 (R Square) sebesar 0,626 atau $(62,6 \%)$. Hal ini menunjukkan bahwa persentase sumbangan pengaruh variabel independen (Lingkungan Kerja dan Karakteristik Individu) terhadap variabel dependen (kinerja karyawan BRI Syariah) sebesar 62,6\% atau variasi variabel independen yang digunakan dalam model (Lingkungan Kerja dan Karakteristik Individu) mampu menjelaskan 62,6\% variabel dependen (kinerja karyawan BRI Syariah), sedangkan sisanya sebesar $37,4 \%$ dipengaruhi atau dijelaskan oleh variabel lain yang tidak dimasukkan dalam model penelitian ini. nilai t hitung untuk variabel Karakteristik Individu adalah sebesar 5,632, sedangkan nilai t tabelnya adalah sebesar 2,020 ( $\mathrm{df}=44$ $2-1=41$ ). Selain itu, nilai signifikansinya adalah sebesar 0,000 lebih kecil daripada taraf signifikansi $(\alpha) 0,05$. Karena nilai $t$ hitung $>\mathrm{t}$ tabel $(5,632>2,020)$ dan nilai signifikansi lebih kecil daripada taraf signifikansi $(\alpha) 0,05(0,000<0,05)$, maka hipotesis kedua diterima, artinya Karakteristik Individu berpengaruh positif dan signifikan terhadap kinerja karyawan BRI Syariah.

Nilai $\mathrm{F}$ hitung adalah sebesar 34,254, sedangkan nilai $\mathrm{F}$ tabelnya adalah sebesar 3,226 (df $1=3-1=2$ dan df $2=44-2-1=41$ ). Selain itu, nilai signifikansinya adalah sebesar 0,000 lebih kecil daripada taraf signifikansi $(\alpha)$ 0,05. Karena nilai F hitung $>$ F tabel $(34,254>3,226)$ dan nilai signifikansi lebih kecil daripada taraf signifikansi $(\alpha)$ $0,05(0,000<0,05)$, maka hipotesis ketiga diterima, artinya Lingkungan Kerja dan P-ISSN : 2460-9595

E-ISSN : 2686-5149

DOI. 10.36908/isbank 


\section{4 | Opan Arifudin, Fenny Damayanti Rusmana, PENGARUH LINGKUNGAN KERJA DAN KARAK....}

Karakteristik Individu secara simultan berpengaruh positif dan signifikan terhadap kinerja karyawan BRI Syariah.

\section{Simpulan}

Berdasarkan hasil penelitian yang dilakukan bahwa hipotesis ketiga diterima, artinya Lingkungan Kerja dan Karakteristik Individu secara simultan berpengaruh positif dan signifikan terhadap kinerja pegawai. Hal ini di tunjukan Karena nilai $F$ hitung > F tabel $(34,254>3,226)$ dan nilai signifikansi lebih kecil daripada taraf signifikansi $(\alpha) 0,05(0,000<0,05)$. Adapun masukan dari hasil penelitian ini adalah lembaga keuangan syariah yang lahir dari semangat mewujudkan nilai-nilai islam secara menyeluruh, perlu didukung dengan kepemimpinan berorientasi memberikan contoh pada pegawainya dan adanya mekanisme rekrutmen pada lembaga keuangan syariah dengan orientasi akhlak pegawai agar saat bekerja pegawai dapat melakukan pekerjaannya sesuai dengan tuntutan syariah yang ada. 


\section{DAFTAR PUSTAKA}

Alam, A. P. 2016. Analisis Kinerja Karyawan Pada Pt. Bank Syariah Mandiri Cabang Aksara Medan Ditinjaudari Manajemen Syariah. Analytica Islamica, Volume 5, No 1, Juni 2016.

Aravik, H., Sulastyawati, D., \& Yunus, N. R. 2020. Leadership Concept At Sharia Bank; A Theoretical Study. Islamic Banking: Jurnal Pemikiran Dan Pengembangan Perbankan Syariah, 5(2), 21-32.

Arifudin, O. 2019. Pengaruh Kompensasi Terhadap Kinerja Karyawan Di PT. Global (PT.GM). Jurnal Ilmiah MEA (Manajemen, Ekonomi, \& Akuntansi), 184-190. Volume 3, No 2, Mei 2019

Arifudin, O. 2020. Analisis Budaya Organisasi Dan Komitmen Organisasi Karyawan Bank Swasta Nasional Di Kota Bandung. Jurnal Ilmiah MEA (Manajemen, Ekonomi, Dan Akuntansi), Manajemen, Ekonomi, dan Akuntansi), 73-87. Volume 4, No 2, Mei 2020

Rahmawanti, N. P., Swasto, B., \& Prasetya, A. 2014. Pengaruh Lingkungan Kerja Terhadap Kinerja Karyawan (Studi pada Karyawan Kantor Pelayanan Pajak Pratama Malang Utara). Jurnal Administrasi Bisnis (JAB). Volume 8, No2, Maret 2014

Mahayanti, I. G. A. K., \& Ayu, S. A. A. 2017. Pengaruh Karakteristik Individu, Karakteristik Pekerjaan, Dan Karakteristik Situasi Kerja Terhadap Kepuasan Kerja Karyawan. E-Jurnal Manajemen Unud. Volume 6, No 4, Juni 2017 
46 Opan Arifudin, Fenny Damayanti Rusmana, PENGARUH LINGKUNGAN KERJA DAN KARAK.... 